\title{
Ciência e Valores: uma leitura epistemologicamente guiada de fontes primárias
}

Marinês Domingues Cordeiro*

\section{Resumo}

Introduzo a temática da relação entre ciência e valores, um problema lógico que tem origem no problema da indução e na crítica ao positivismo lógico, com o escrutínio do conceito de subdeterminação. O objetivo geral é apresentar duas teses filosóficas com capacidade heurística bastante interessante para o Ensino de Física e de Ciências, em geral, sobretudo àqueles que, trabalhando com história da ciência no ensino, gostariam de poder examinar os potenciais filosóficos de algumas fontes primárias. O modelo triádico de justificação, desenvolvido por Larry Laudan, é um construto simultaneamente crítico ao positivismo e ao pós-positivismo. Por ser focado precisamente na justificação, tem o poder de permitir as análises de documentos como as Conferências Nobel, por exemplo. Reconhecendo a relação reticulada entre métodos, teorias e objetivos que faz um cientista ou uma comunidade, é possível olhar esses documentos e compreender o processo de racionalização ao qual eles aludem. Analiso a Conferência Nobel de Marie Curie, de modo a mostrar as inter-relações e ajustes entre métodos, teorias e objetivos anunciados pela física, em 1911, que culminaram em uma reestruturação da própria Química. Prosseguindo em relação às teses filosóficas, a ciência como conhecimento social, defendida por Helen Longino, é apresentada e, especificamente a importância dos tipos de crítica intersubjetiva, evidenciais e conceituais, elencados pela filósofa. Tais críticas servem de instrumento heurístico para a análise do trabalho "Sobre o elemento 93" de Ida Noddack, revelando como a subdeterminação de certas evidências pode gerar novas hipóteses, como neste caso, a da fissão nuclear.

Palavras-chave: Subderteminação. Justificação. Radioatividade. Crítica Intersubjetiva. Fissão Nuclear.

Doutora em Educação Científica e Tecnológica. Professora do departamento de Física da Universidade Federal de Santa Catarina. E-mail: marines.ufsc@ufsc.br. ORCID: https://orcid.org/0000-0001-9102-7441

https://doi.org/10.5335/rbecm.v4i3.12904

http://creativecommons.org/licenses/by-nc-nd/4.0

ISSN: 2595-7376 


\section{Cisne negro, lógica e justificação - um prelúdio}

Quando se trata de fenômenos naturais, observação e indução desempenham papel importante na maneira como erigimos nossos conhecimentos. Não à toa, no período que demarca o nascimento da ciência moderna, a noção de que bons conhecimentos são oriundos da observação controlada e do processo de indução deu origem à concepção empírico-indutivista da ciência. É fato reconhecido que esse paradigma metodológico estava fortemente atrelado a uma necessidade histórica de divórcio da filosofia escolástica e à confiança nas capacidades humanas de intervir na natureza de acordo com representações descritivas oriundas das observações.

Não obstante, as representações da natureza são justamente isso: representações. Não demorou para que a capacidade lógica do indutivismo fosse problematizada. Não é porque se viam cisnes brancos na Europa que eles só existiam nessa penugem. Esse, que é o renomado problema da indução de David Hume, revela as limitações lógicas da indução: um determinado conjunto de evidências não pode garantir, além da razoabilidade, uma afirmação de natureza generalista.

Com a paulatina sofisticação da ciência e dos objetos por ela investigados, foi ficando claro que a atitude metodológica dos cientistas vai muito além da observação e da inferência por indução. Experimentos são desenvolvidos à luz de corpos teóricos, ou ao menos, de conviçcões teóricas ou metateóricas. Mesmo em áreas da ciência cujos paradigmas teóricos pioneiros não tinham a consolidação da atualidade, como no caso dos estudos de eletricidade, elas envolviam o desenvolvimento de novos dispositivos, capazes de promover fenômenos que não ocorrem espontaneamente na natureza. A garrafa de Leyden e seu papel para as explorações de Benjamin Franklin é um exemplo. Assim, outro problema do mito empírico-indutivista surge, demarcado agora por Pierre Duhem: a confiabilidade das observações. Não há neutralidade nas observações, afinal de contas; o que se torna evidência é, também, um caso de interação entre objeto e sujeito. São problemas cujas tentativas de resolução passaram por questões de plausibilidade e refutabilidade. Enquanto todos os cisnes parecerem brancos, é possível afirmar que essa é provavelmente uma de suas características demarcadoras.

Willard Quine elevou essas problematizações lógicas a outro patamar, asseverando que nossas incertezas acerca do nosso conhecimento nos obrigam a avaliar e, em última instância, aceitar, múltiplas teorias explicativas para um mesmo estado de coisas. É a tese da subdeterminação: nenhum conjunto de evidências consegue 
conduzir inequivocamente a uma teoria. Mesmo que pareça contornada com o apelo a questões de plausibilidade e refutabilidade, constatar que nossos conhecimentos são subderterminados abre espaço para questionamentos ainda mais complexos: o que nos leva a fazer a mediação entre as observações e as afirmações generalistas? O que nos faz compreender algo como uma evidência para determinada hipótese? Naturalmente, são capacidades cognitivas que, elas próprias, não podem ser colocadas em teste. São juízos, que têm suas raízes em diversas estruturas mentais que evoluíram conosco.

Kuhn (2006) marcou época na filosofia ao avaliar que, nos períodos que ele chamou de revolução científica, eram necessários não apenas argumentos de convencimento, aqueles hipoteticamente arraigados na lógica e na estrutura cognitiva típica da ciência. Também a persuasão fazia parte desses momentos da história da ciência, isto é, a orientação à concordância, por variados motivos, de variadas naturezas. Para defender-se dos críticos, que viam na sua visão de ciência o fim da racionalidade, Kuhn (2009) trabalhou justamente esses juízos, tentando mostrar que eles não são, necessariamente, emblemáticos de irracionalidade.

Para ele, a visão positivista de que um dissenso acerca da escolha teórica deveria ser finalizado com a avaliação de determinadas regras para o conhecimento precisava ser revista, já que tais regras subdeterminam as escolhas teóricas. Ele elencou cinco dessas regras: precisão, coerência, alcance, fertilidade e simplicidade. Sua defesa é a de que elas agem como valores, porque dependem do significado dado a cada um pelos cientistas, ou seja, precisam ser ponderados, individual e coletivamente. Ademais, podem ter importâncias diferentes dentro da comunidade científica. São aspectos que, simultaneamente, envolvem objeto de conhecimento e sujeito cognitivo. Os valores da atividade científica, enfim, subdeterminam a escolha teórica. Em última instância, havendo dissenso, precisam ser ponderados. A escolha teórica, para Kuhn (2009), envolve um processo interino de discussão, negociação e adaptação ao novo conhecimento. Com isso, uma espécie de homogeneização das percepções da comunidade ocorre, mesmo que entrementes vozes dissidentes ainda subsistam.

Por mais criticado que ainda tenha sido, tanto por positivistas quanto por outros filósofos, é essencial considerar a fertilidade da sugestão de Kuhn (2009). Por um lado, ele expõe que os juízos de valor vão muito além de questões de probabilidade, embora recorra a ela, apologeticamente, ao fim daquele ensaio; por outro ele busca mostrar como juízos de valor não são necessariamente marcas de irracionalidade. Restou, para os filósofos que buscavam se afastar do relativismo, a tarefa de com- 
preender como essas duas novas dimensões podem ser atreladas à objetividade e à racionalidade da ciência.

Neste trabalho, apresento algumas ideias de dois desses filósofos, Larry Laudan e Helen Longino. Em Laudan (1984), há um movimento de compreender a justificação de um conhecimento científico e, nesse sentido, uma nova visão de racionalidade da ciência. No caminho, notou que os sentidos evidência-hipótese e valores-teorias não são os únicos subdeterminados; mobilizando três dimensões científicas - teorias, métodos e objetivos da ciência - ele vê que os cientistas julgam não apenas as qualidades das evidências, mas também as dos métodos e dos objetivos. A justificação de uma escolha teórica é, enfim, uma rede de negociações entre todas essas dimensões e assim como Kuhn, defende que os objetivos da ciência não são juízes supremos, em última instância, das melhores teorias e métodos. Eles próprios não estão imunes a escrutínio e ressignificação; a visão de Laudan, no entanto, é de que esses deslocamentos são geralmente justificados por métodos e evidências.

Em Longino (1990), vemos a reinterpretação da ideia de objetividade, que depende não apenas dos âmbitos de escolha teórica, mas de todos os outros na ciência - escolha de dados, associação de suposições gerais e específicas, tratamento de evidências, etc. São todas partes da ciência abertas a juízos de valor; apenas a crítica intersubjetiva pode ter a capacidade de revelar esses valores, que podem ser tradicionalmente cognitivos, mas também contextuais. Ao examinar a maneira como valores se tornam constitutivos da ciência (sejam eles contextuais ou tradicionalmente cognitivos) e como a crítica intersubjetiva pode, amiúde, conferir graus de objetividade à prática científica, Longino (1990) enxerga a dimensão lógica da ciência como potencial legado de sua característica social.

Escolhi esses dois referenciais, porque o objetivo deste trabalho não é apenas o de apresentar novas visões filosóficas das questões relativas a ciência e valores. Da maneira como justificaram suas teses, eles trazem mecanismos com forte capacidade heurística para a interpretação de documentos científicos. As articulações entre as asserções de natureza teórica, metodológica e axiológica, presentes na visão de Laudan (1984), podem elucidar a leitura de alguns documentos com forte base na justificação, como as Conferências Nobel. Como exemplo, analiso a proferida por Marie Curie, em 1911 (CURIE, 1966), em que a física delineia os intrincados caminhos trilhados para justificar o rádio como elemento químico bem definido - e, por consequência, todas as outras substâncias radioativas imponderáveis. 
Defendo que o ponto de vista de Longino (1990), de que a ciência é uma atividade social de permanente crítica, pode ser particularmente profícuo para a leitura guiada de artigos científicos, em particular aqueles que contêm avaliação e crítica de hipóteses antecessoras. Com apoio na distinção entre críticas evidenciais e críticas conceituais, perscruto o exemplo do artigo de Ida Noddack (1934) - Sobre o elemento 93 - que, diante da hipótese da produção de elementos transurânicos por Enrico Fermi (1934), mostra as lacunas evidenciais da pesquisa do italiano e constrói, na forma de hipótese conceitualmente possível, a quebra dos núcleos, cinco anos antes do que socialmente se entende ter sido a descoberta da fissão nuclear (HAHN; STRASSMANN, 1939; MEITNER; FRISCH, 1939).

Filosofia e história não podem trabalhar dissociadas; essa máxima atribuída a Imre Lakatos tem importância especial para a educação científica. Nem sempre, fontes primárias são elusivas ao educador. Com o auxílio da filosofia da ciência, há certos documentos científicos capazes de serem didatizados, caso seja objetivo do educador o endereçamento de questões acerca das capacidades da ciência, sua racionalidade e objetividade. Em tempos em que o negacionismo suprime o salutar ceticismo, espero conseguir mostrar que a discussão sobre como são sólidas, mesmo diante da subdeterminação, as capacidades da ciência de se justificar a partir da crítica pode ter um espaço em sala de aula.

\section{Justificar}

Então temos o caso da subdeterminação, que pode parecer, inicialmente, um caminho inexorável à irracionalidade, ou ao menos ao relativismo. Kuhn (2009) tentou trabalhar o conceito dentro da perspectiva da escolha teórica, quando o cientista deve fazer juízos de valor (cognitivo) e, em última instância, negociar tais escolhas em comunidade. Contudo, sua defesa da gênese do dissenso, pujante em A Estrutura das Revoluções Científicas (KUHN, 2006), parece ser muito mais robusta do que a maneira como ele vislumbra a restauração do consenso pela comunidade científica. E, como afirma Laudan (1984), em comparação com outras áreas do conhecimento como a sociologia e a filosofia, o consenso talvez seja uma das características mais exuberantes das ciências ditas duras.

Para entender o processo de consensualização na ciência, ele volta-se aos positivistas, que trabalharam, de fato, no paradigma do consenso, da lógica e da justi- 
ficação. Muitos deles defendiam uma espécie de modelo hierárquico de justificação: havendo dissenso sobre hipóteses, cientistas buscam a justificação na metodologia; havendo dissenso em questões metodológicas, buscam a resposta nos objetivos da ciência. Naturalmente, como já falei, não há garantias de que os próprios objetivos da ciência não sejam subdeterminados, argumento de Kuhn (2009) e Laudan (1984), e fato que espero elucidar com a análise da Conferência Nobel de Marie Curie (1911, 1966). Laudan (1984) não deixa escapar esse fato, mas se pergunta: com efeito, a subdeterminação, em todos os âmbitos, é determinante de um relativismo científico? Sua resposta é não.

Para ele, um melhor modelo de justificação não é hierárquico, mas reticulado, ou seja, uma rede de demandas entre teorias, métodos e objetivos da ciência. Nessa relação reticulada, as negociações são mais sólidas, demandam deslocamentos cognitivos, ampliam o escopo dos entendimentos acerca de fenômenos e conceitos, ensejam novas fenomenotécnicas. A figura abaixo é emblemática da compreensão de Laudan (1984) sobre a justificação de um conhecimento.

Figura 1: Rede triádica ou modelo triádico de justificação de Laudan (1984)

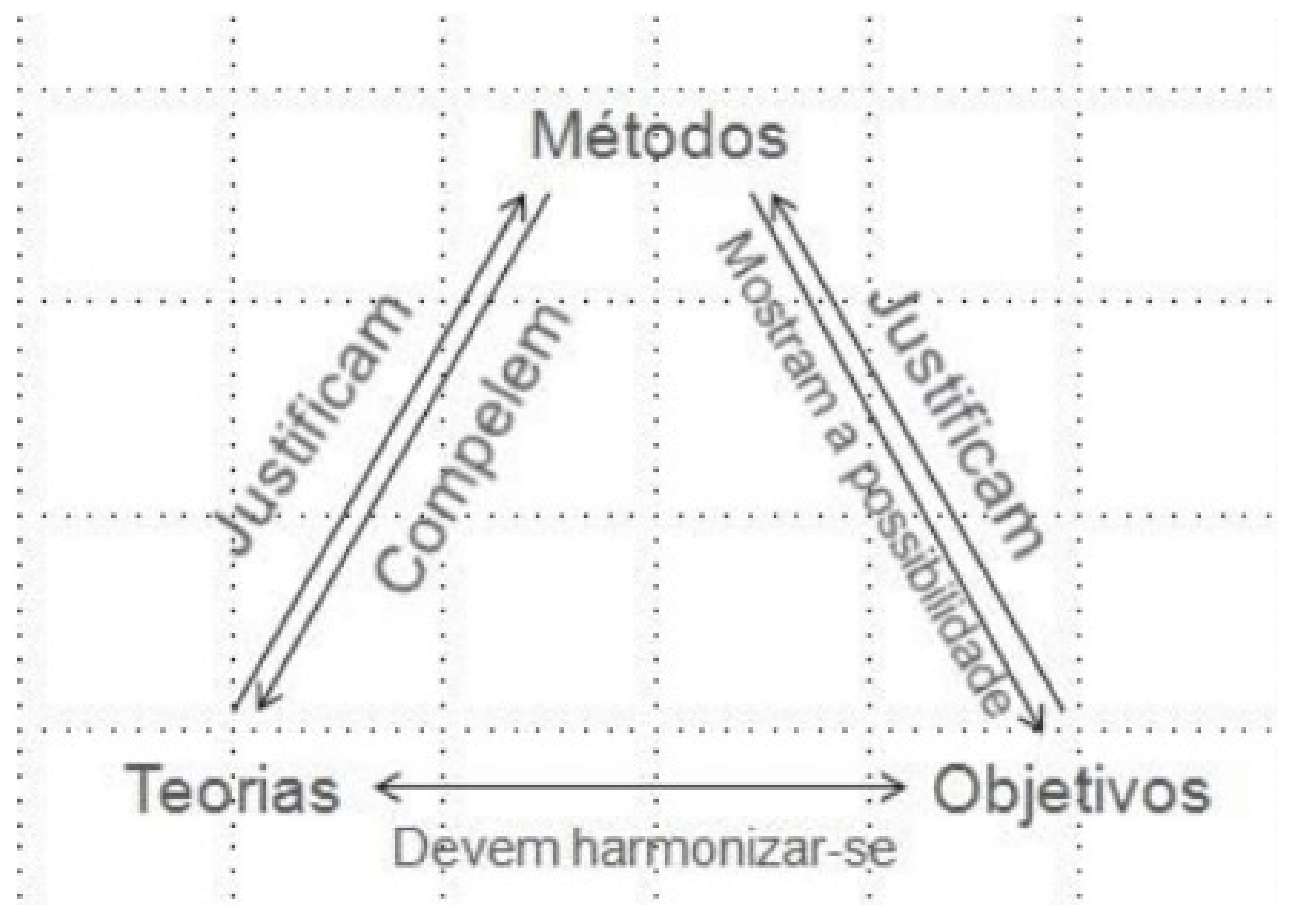


Com a estrutura de uma rede, pode-se notar que, apesar de haver disputas entre variados níveis, eles são mobilizados perenemente. É isso que pode explicar, entre outras coisas, a falácia de que, havendo consenso fatual, não há divergências na ciência. O consenso é, para ele, saudavelmente constituído de dissensos; isso pode explicar como os cientistas podem concordar teoricamente, mesmo tendo diferenças axiológicas entre si. "[O] modelo reticulado insiste que, em relação a quais teorias são sólidas, nossos julgamentos podem ser avaliados com referências às nossas axiologias explícitas, de modo a revelar tensões entre nossas estruturas de valores implícitas e explícitas" (LAUDAN, 1984, p. 62). E ele segue, tentando defender uma nova concepção de racionalidade:

Mas, além de exigir que nossos objetivos cognitivos devam refletir nossas melhores crenças do que é ou não possível, que nossos métodos devam ter uma relação apropriada com nossos objetivos, que nossos valores implícitos e explícitos devam ser sincronizados, há pouco mais que a teoria da racionalidade possa demandar (LAUDAN, 1984, p. 64).

É natural que vejamos, em Laudan (1984) uma rigidez da concepção da ciência, por duas razões: em primeiro lugar, por buscar nos positivistas um panorama sobre o qual trabalhou e reformou; em segundo, porque sua visão demanda afastamento, ou uma espécie de retrospectiva. Analisando as interações localizadas, na instância exemplar dos microcosmos das controvérsias científicas, não fica claro como tais domínios se relacionam à maneira do filósofo. Contudo, é pertinente notar que seu modelo é de justificação - ou, de certa forma, uma visão ampla e historicamente situada da ciência. Não é um bom instrumento heurístico para avaliar as interações entre cientistas desde uma perspectiva hiperfocada, mas uma maneira de olhar o episódio quando o consenso é atingido, para entender como ele sequer foi atingido. Para este fim, há documentos científicos com uma perspectiva ampla, uma reconstrução racional dos acontecimentos, documentos de máxima justificação, enfim. Conferências ministradas por cientistas depois da consolidação das teorias que propuseram têm geralmente tais características.

As Conferências Nobel são grandes exemplos desse tipo de documento. Para a educação científica, elas são fontes históricas primárias singulares. Por serem ministradas ao público leigo, têm uma linguagem mais acessível e menos científica. Também fornecem a perspectiva única do cientista protagonista, que tem o hábito de citar os colegas com quem trabalhou e que ampliaram as investigações, e demonstra sua compreensão acerca da epistemologia e da ontologia daqueles fenômenos. 
Ademais, são de fácil acesso, já que estão no portal do Prêmio Nobel ${ }^{1}$, em inglês; podem ser encontradas com a simples redação do nome do cientista laureado no mecanismo de busca da página.

\section{Justificando os novos elementos radioativos}

É fato amplamente conhecido que Marie Curie, além de ser uma das poucas mulheres nobelistas, foi a única laureada, entre homens e mulheres, em duas ciências. No que pode, a olhos incautos ${ }^{2}$, aparentar uma ação vanguardista do Comitê Nobel - afinal, em 1903, apenas o terceiro ano das premiações, as universidades europeias mal se abriam às mulheres, e os cursos científicos eram especialmente inóspitos àquelas que se propunham ao desafio - Curie dividiu uma das metades do prêmio da física com seu marido, Pierre. Na ocasião, a láurea ao casal deveu-se à descoberta da propriedade atômica da radiatividade; oito anos mais tarde, a física voltaria a ganhar, desta feita na química e sem compartilhamento, pelo que comumente se atribui à descoberta dos elementos rádio e polônio.

Entre 1903 e 1911, muitas coisas aconteceram nas vidas pessoal e profissional de Marie Curie, assim como no desenvolvimento da própria ciência da radioatividade. O rádio, que ela e seu marido alegaram ter descoberto já em 1898, estava apenas disponível na forma de sal enriquecido, e não isolado, como os cânones da química na época demandavam. Contudo, a comunidade de radiocientistas $^{3}$ na primeira década do século 20 não parecia se opor à ideia de que o rádio e o polônio eram elementos químicos. A concepção da radioatividade como fenômeno atômico provia sólidas evidências desse novo e quase imponderável elemento; ademais, era muito fértil e permitiu o desenvolvimento de novos horizontes conceituais e uma progressiva evolução na própria concepção de matéria.

Com o discernimento das radiações em alfa, beta e gama, seguido da identificação da partícula alfa com o hélio duplamente ionizado ${ }^{4}$, feita por Rutherford, a radioatividade passou a ser compreendida como um decaimento, uma transmutação de elementos. Revelava-se, portanto, que urânio e tório, ao emitir tais partículas, se transformavam em outros elementos, em sucessivas emissões. Várias séries de decaimento foram diferenciadas, geralmente terminando na formação do chumbo. O uso do espectro e da ionização, frutos de metodologia óptica e elétrica, tornou-se fundamental, dado que, em tais séries, certos elementos tinham meias-vidas muito 
curtas e encontravam-se em condições imponderáveis para a medição precisa de suas massas atômicas, algo essencial para a química dos elementos ponderáveis.

Em razão de o chumbo ser o produto final mais básico das séries radioativas naturais e de a partícula alfa ser identificada com o hélio, esses dois elementos químicos sempre eram encontrados em quantidades ponderáveis nas amostras minerais estudadas, diferentemente do rádio e do polônio, por exemplo. Assim, em 1906, ano em que faleceu Pierre, uma objeção à existência do rádio foi levantada por Lorde Kelvin, que sugeriu que o elemento era de fato uma composição de chumbo e hélio (MCGRAYNE, 1995). Embora não fique explícita na Conferência Nobel proferida por Marie, tal sugestão parece ter promovido um redirecionamento das ações de pesquisa da física, como uma análise baseada na rede de relações entre evidências, métodos e valores de sua aula pode indicar.

Intitulada "Rádio e os novos conceitos em Química", a Conferência é uma narrativa histórica do desenvolvimento da radiatividade e, como o título não deixa escapar, da relação entre a descoberta do rádio e da construção de uma nova maneira de se fazer química. Bastante didática, ela tacitamente enfatiza seu objetivo ao asseverar: "[n]este campo, a importância do rádio do ponto de vista das teorias gerais foi decisiva. A história da descoberta e do isolamento dessa substância forneceu provas da minha hipótese de que a radioatividade é uma propriedade atômica da matéria e pode prover meios de busca por novos elementos" (CURIE, 1911; 1966, in CORDEIRO; PEDUZZI, 2010, p. 486).

Uma asserção de clara natureza fatual, “[u]ma primeira prova de que o rádio existia" (ibid., p. 489), inicia o processo de justificação metodológica do rádio como novo elemento, quando Curie enfatiza que a análise espectral de um cloreto exibia uma nova linha, que ficava mais forte, conforme era enriquecido por cristalização, associada ao desaparecimento de linhas características do bário. Ela continua solidificando as justificativas metodológicas apontando desenvolvimentos posteriores para a determinação da massa atômica daquele metal, que aumentava segundo o enriquecimento, apontando inclusive as medidas da massa atômica que se configuravam como evidência. Ela segue defendendo a coerência de se compreender o rádio como um metal alcalino-terroso com a estrutura da Tabela Periódica, a partir de suas similaridades com o bário e apresentando suas características elétricas e ópticas. Culmina, depois disso, lembrando que ela e Debierne isolaram o rádio no estado metálico em 1910 - minuciando os métodos desenvolvidos por eles para tal objetivo. 
Nestes cinco parágrafos de sua Conferência, características típicas da concepção kuhniana de agregação de valores cognitivos a um determinado conhecimento ficam bastante claras. Coerência, precisão e alcance são características atribuídas por Curie aos resultados da pesquisa sobre o rádio. Mas sua Conferência quer ir mais longe: quer mostrar a fertilidade da concepção do elemento rádio, muito antes de seu isolamento, para alterar os objetivos e a maneira de se fazer química, especificamente a química dos elementos imponderáveis - o que explicaria os empecilhos com o polônio, ainda mais difícil de enriquecer que o rádio. Ela usa esse aspecto de natureza axiológica para construir seu argumento a partir de mais uma asserção de natureza fatual.

As propriedades radioativas do metal são exatamente aquelas que podem ser previstas, assumindo-se que a radioatividade dos sais é uma propriedade atômica do rádio, cujo estado de combinação não afeta. Era de real importância corroborar esse ponto, conforme dúvidas eram levantadas por aqueles que não aceitavam a hipótese atômica da radioatividade (ibid., p. 490).

Um mineral rico em polônio, ela explica, contém quantidades baixíssimas desse elemento. Se conseguir isolá-lo era uma tarefa quase impossível, a experiência desenvolvida para o rádio efetivamente indicou as asserções metodológicas para determinar a identidade do polônio e outros elementos radioativos imponderáveis essa, por sua vez, uma afirmação do domínio teórico. O caminho, no entanto, não deixou de passar pela tentativa de isolar o polônio: "consegui produtos com atividades muito altas sem, no entanto, chegar a resultados definitivos, como no caso do rádio" (ibid., p. 490). A curta meia-vida do polônio era a principal dificuldade. A análise espectral foi decisiva nesse ínterim e mostrava grande sintonia com as expectativas axiológicas e teóricas. "De acordo com a hipótese atômica da radioatividade, o espectro do polônio deveria desaparecer ao mesmo tempo em que sua atividade, e esse fato pode ser confirmado experimentalmente" (ibid., p. 491). Aqui, observa-se uma ênfase na rede de interações entre valores (precisão), métodos (óptico e elétrico) e evidências (o polônio como elemento químico).

Importa ressaltar, então, que não apenas os Curie trabalhavam com radioatividade, mas também vários outros grupos de pesquisadores pelo mundo, entre eles Rutherford e Soddy. Buscando compreender o que acontecia naquelas emissões de energia, chegaram à conclusão de que ocorria ali uma desintegração atômica, isto é, que a emissão de radiação alfa e beta envolvia a transformação de elementos 
em outros. Não apenas a teoria de Rutherford e Soddy é enunciada por Curie, mas também as evidências que a suportam:

não se pode contestar que o elemento químico perfeitamente definido rádio permite a formação de outro elemento químico bem definido - o hélio [...] Devo frisar aqui que a arrojada interpretação da relação existente entre rádio e hélio se apoia inteiramente na certeza de que o rádio tem todas as características de um elemento químico, como têm todos os outros elementos conhecidos (ibid., p. 492).

Com base na experiência com ponderáveis, começou-se a traçar as famílias de decaimento; o rádio sendo um produto do urânio, o chumbo sendo o elemento final mais usual dos decaimentos e o polônio, um imponderável, mas reconhecido por uma linha espectral característica, como um produto intermediário entre o rádio e o chumbo. A ênfase nesta linha de narrativa é demonstrar que a combinação de métodos tradicionais da química com aqueles oriundos da novíssima ciência da radioatividade consolidavam a existência do polônio. E, como se não fosse $o$ bastante, com quantidades enriquecidas de polônio - uma asserção conceitual - Curie e Debierne foram bem-sucedidos em desenvolver um método para determinar o número de Avogadro, uma constante canônica da química.

Olhar um documento como a Conferência de Marie Curie com os olhos voltados às três dimensões da ciência esclarece pujantemente as dificuldades envolvidas em justificar um conhecimento e a riqueza das inter-relações entre novas teorias e o cânone. Ademais, propicia compreender que não existe um único sentido de justificação, como propunham os positivistas, assim como é possível compreender o tipo de racionalidade que rege as ações dos cientistas, mesmo diante da subdeterminação. Fica claro, como apontou Laudan (1984), que valores, métodos e evidências interagem como uma rede e que o tecer histórico dessa rede demanda novos olhares, coletividade, crítica, criatividade. Não raro, inclusive, esse árduo caminho leva a alterações dos próprios objetivos maiores da ciência, uma reformulação de como ela se vê e se determina, como vê e determina seus objetos, não apenas uma adaptação, mas uma mudança maior na dimensão axiológica.

É a esse ponto que Curie quer chegar, quando ao fim de sua aula, reiterando as associações entre metodologias clássicas e atuais, novas teorias e concepções canônicas, redimensionamento de valores cognitivos como precisão, coerência, alcance e fertilidade, ela explica que o sucesso do rádio permitiu a identificação (não apenas no sentido de descoberta, mas sobretudo no sentido de aceitação, de consensualiza- 
ção) de variados outros elementos, entre eles o polônio, que não poderiam ser assim compreendidos se não fosse a grande reformulação pela qual a química passava, mediada pelo fenômeno da radioatividade.

Também estamos acostumados, atualmente, a lidar em laboratório com substâncias cujas presenças apenas nos são mostradas por suas propriedades radioativas, mas que, mesmo assim, podemos determinar, dissolver, reprecipitar de suas soluções e depositar eletroliticamente. Isso significa que nós temos aqui um tipo completamente distinto de química, para a qual a ferramenta mais utilizada é o eletrômetro e não a balança, e que podemos chamar de química de imponderável (ibid., p. 494).

\section{Criticar}

Não sem razão, Laudan (1984) batiza seu modelo de rede triádica da justificação; seu objetivo, afinal, é sustentar uma nova perspectiva de racionalidade científica, uma que seja capaz de explicar o alcance do consenso na ciência, mesmo que haja dissensos entre cientistas dentro das três dimensões da ciência. Neste sentido, as Conferências Nobel em geral são documentos que podem perfeitamente bem ser analisadas a partir da perspectiva da rede triádica. A qualidade justificativa delas é vigorosa, por serem a reconstituição histórica de uma hipótese ou teoria que ganhou a maior das láureas da ciência.

Também é fundamentado, neste sentido, que a visão de Laudan (1984, p. 65) seja impregnada de valores cognitivos, aqueles típicos da ciência - justamente porque seu objetivo é o de entender, mesmo que de um ponto de vista retrospectivo, as justificações acerca do progresso da ciência. "Quando nos perguntamos se a ciência progrediu, estamos tipicamente perguntando se o desenvolvimento diacrônico da ciência nos aproximou das finalidades cognitivas que julgamos merecidas e desejáveis". Todavia, cabe questionar: que mecanismos ocorrem ao longo da ciência, nos permanentes ajustes executados pelos cientistas nas suas interpretações acerca das melhores evidências e dos melhores métodos, que permitem vislumbrar os objetivos da ciência e se eles estão de acordo com valores desejáveis? Como revelar os valores que direcionam as pesquisas, as interpretações, as escolhas de evidências? São perguntas que, entre outras coisas, demandam entender quais partes da prática científica foram afetadas não apenas por valores cognitivos, mas aqueles contextuais, que podem ter tido efeito constitutivo nas tomadas de decisões por parte dos cientistas. 
Criadora de pequenos e grandes dissensos na ciência, a crítica entre os cientistas, chamada por Longino (1990) de crítica intersubjetiva, é defendida pela filósofa como a resposta para as questões supracitadas. Se é possível para Laudan lançar um olhar histórico a partir dos objetivos do presente e compreender as estruturações da rede de justificação, para Longino (1990), a perspectiva interessante é a de buscar quais críticas fomentaram a adaptação na prática científica. Sem a crítica, afinal, a rede de Laudan sequer teria espaço e o modelo hierárquico de justificação seria um bom modelo para entender a construção do conhecimento, que seria cumulativa, pouco emblemática das capacidades e curiosidades humanas e, acima de tudo, falha logicamente. Como bem afirma Longino (1990, p. 74)

De um ponto de vista lógico, se o conhecimento científico fosse entendido como a simples soma de produtos finalizados de atividades individuais, então não apenas seria impossível bloquear ou mitigar as influências de preferências subjetivas, mas o próprio conhecimento seria uma miscelânea de teorias divertidamente inconsistentes. Somente se os produtos da investigação forem compreendidos como formados pelo tipo de discussão crítica que é possível entre uma pluralidade de indivíduos acerca de um fenômeno comumente acessível, conseguimos notar como eles podem ser considerados como conhecimento, e não como opinião.

Por conveniência, Longino divisa dois tipos de críticas geralmente erigidas pelos cientistas para perscrutar uma hipótese: evidenciais e conceituais. As críticas evidenciais estão diretamente ligadas aos procedimentos de coleta e apresentação de evidências, empíricas ou teóricas, para o suporte de determinada hipótese. São as críticas que questionam a precisão e o alcance das evidências para a hipótese.

Em relação às críticas conceituais, que foram "frequentemente estigmatizadas como 'metafísicas", Longino (1990, p. 72) reitera que elas recebem menos atenção na filosofia, em comparação às críticas evidenciais, que em geral mobilizam a avaliação de valores cognitivos mais tradicionais, como a adequação empírica. Nesta categoria de críticas, ela distingue três subclassificações: (i) críticas acerca da solidez conceitual de uma hipótese, algo como sua consistência; (ii) a coerência de uma hipótese com teorias aceitas, canônicas, e (iii) a crítica que questiona a relevância das evidências apresentadas para suportar uma hipótese. Esta terceira, uma espécie de contra via das críticas experimentais, é capaz de, diante da revelação da subdeterminação, mostrar que uma outra hipótese é presumível e transparecer os valores que mediaram uma interpretação teórica ou outra. 
Assim, a maior parte do debate se centra não nos dados, mas nas suposições à luz das quais os dados são interpretados. Essa última forma de crítica, embora relacionada a considerações evidenciais, é agrupada às formas de crítica conceitual, porque se ocupa não como com a precisão com que os dados foram medidos e reportados, mas com as suposições à luz das quais esses dados são tomados como evidência para uma dada hipótese, em primeiro lugar. Aqui, não é o próprio material que é argumentado, mas sua relevância para a hipótese (LONGINO, 1990, p. 72-73).

Importa ressaltar, enfim, que a tese de Longino (1990), que ela chama de ciência como conhecimento social, tem na subdeterminação o fundamento para a construção da ponte para uma filosofia historicamente acurada e logicamente sólida, justamente por focar nas críticas feitas por cientistas que podem revelar os valores mobilizados nas escolhas de hipóteses. O efeito dessas críticas, sobretudo do terceiro tipo de crítica conceitual, é o de revelar subjetividades ou contextualidades que podem ter operado em uma prática científica, sugerir outras hipóteses, quando conveniente, e as expor a novas críticas. Deste modo, ela propõe uma nova perspectiva para a questão da objetividade, não uma objetividade atrelada à correspondência, a uma espécie de objetividade ontológica, mas, efetivamente, à sua dimensão metodológica.

A fissão nuclear é um fenômeno amplamente conhecido, ensinado inclusive na educação básica. Apesar de ser um tema moderno na física, uma didatização simples é suficiente para que alunos adolescentes o compreendam. Ademais, tem forte apelo contextual, em virtude de suas aplicações energéticas e bélicas. Há um documento científico, o artigo da química analítica alemã Ida Noddack (1934), cuja leitura é relativamente acessível, em que critica a interpretação de Enrico Fermi (1934) para seus estudos - o de que produzira elementos transurânicos pela primeira vez - afirmando ser igualmente plausível que, em suas investigações, tivesse levado a cabo uma quebra dos núcleos atômicos. Sua interpretação - aceita como correta na atualidade - antecipou em cinco anos a descoberta socialmente aceita da fissão nuclear. O artigo mobiliza, com impressionante clareza, as críticas evidenciais e conceituais enunciadas por Longino (1990).

\section{Criticando os elementos transurânicos}

Como mostrei, nas primeiras décadas do século 20, a descoberta do fenômeno da radioatividade promoveu uma rápida evolução nas metodologias e nos próprios objetivos da química. É fundamental destacar, ainda, que houve uma grande transformação também na física. Da teoria da desintegração atômica, foi possível detectar 
trinta novos elementos de que falava Curie em sua Conferência, posteriormente identificados como isótopos de elementos conhecidos. Os estudos com partículas alfa levaram ao desenvolvimento do modelo atômico nuclear de Bohr-Rutherford e o uso do número atômico, baseado na carga positiva do núcleo, permitiu a reorganização da Tabela Periódica. Em 1919, Rutherford detectou o próton.

Nos anos de 1920, contudo, o domínio fatual de tais pesquisas pareceu estagnar, apesar dos avanços metodológicos para determinações de meias-vidas, isótopos e variadas séries de decaimento. O maior problema residia na dificuldade de investigar os núcleos, já que os projéteis disponíveis, partículas alfa e prótons, eram carregados, portanto submetidos às barreiras coulombianas dos grandes átomos. Outra grande questão se impunha, acerca do limite mais alto da tabela periódica, o urânio. Com suas emissões alfa características, ele produzia elementos de menor número atômico; seria possível produzir um elemento transurânico, caso ele emitisse radiação beta. Entretanto, as experiências pareciam demonstrar que esse era um caminho implausível; ademais, nunca se havia notado, na forma natural, o elemento 93.

O panorama começa a mudar na década de 1930, com as descobertas do nêutron, do pósitron e da radioatividade induzida. Sobre este último, Irène e Frédéric Joliot-Curie conseguiram produzir o fenômeno da radioatividade, em elementos que não eram naturalmente radioativos, com o uso de partículas alfa. Uma reação exemplar deste tipo foi promovida ao bombardear o boro com partículas alfa, produzindo um radioisótopo de nitrogênio e um nêutron. Oportunamente, esse isótopo decaía em carbono, com a emissão de um pósitron. A partir dessa descoberta, a radioatividade deixava de ser um fenômeno exclusivo dos elementos pesados. De fato, uma descoberta de grande importância, que rendeu à filha e ao genro de Marie Curie o Prêmio Nobel de Química de 1935.

Enrico Fermi e sua equipe, na Itália, passaram a investigar a indução da radioatividade com nêutrons. Uma perspectiva não considerada por outros grupos, já que as fontes de nêutrons não pareciam suficientemente efetivas para um bom exame dos núcleos atômicos. Por outro lado, o insight metodológico de Fermi era fundamentado: mesmo em menor quantidade, os nêutrons seriam projéteis melhores, já que não se submetem a interações elétricas. Uma reação exemplar realizada por Fermi foi o bombardeamento do iodo com um nêutron lento; produzindo um radioisótopo do iodo, que emitia radiação gama e, posteriormente, decaía em xenônio, com a emissão de um elétron. Em outras palavras, Fermi conseguira produzir um elemento de maior número atômico ao induzir radioatividade no iodo com o auxílio do nêutron. 
Ao executar a reação com o urânio, Fermi notou a produção de alguns isótopos já bem conhecidos, mas um desconhecido. Uma meia-vida de 13 minutos que emitia partículas beta, com comportamento bastante diferenciado. Nela, promoveram uma série de testes; descartaram sua identidade com elementos naturalmente radioativos, menos o polônio. Notaram, também, que aquela meia-vida tinha características do rênio. Àquela época, a série dos actinídeos que hoje vemos na atual tabela periódica ainda estava em discussão entre os químicos, sendo, portanto, desconhecida dos físicos. Assim, o urânio era considerado um metal de transição e se localizava abaixo do tungstênio (figura 2). Nestas condições, o novo elemento estaria na casa abaixo do rênio. As similaridades químicas entre o elemento recém-produzido e o rênio pareciam indicar, portanto, a produção do elemento 93. Cautelosamente, Fermi publica o artigo intitulado Possível produção de elementos de número atômico acima de 92 (FERMI, 1934), na revista Nature.

Figura 2: Tabela periódica em 1934.

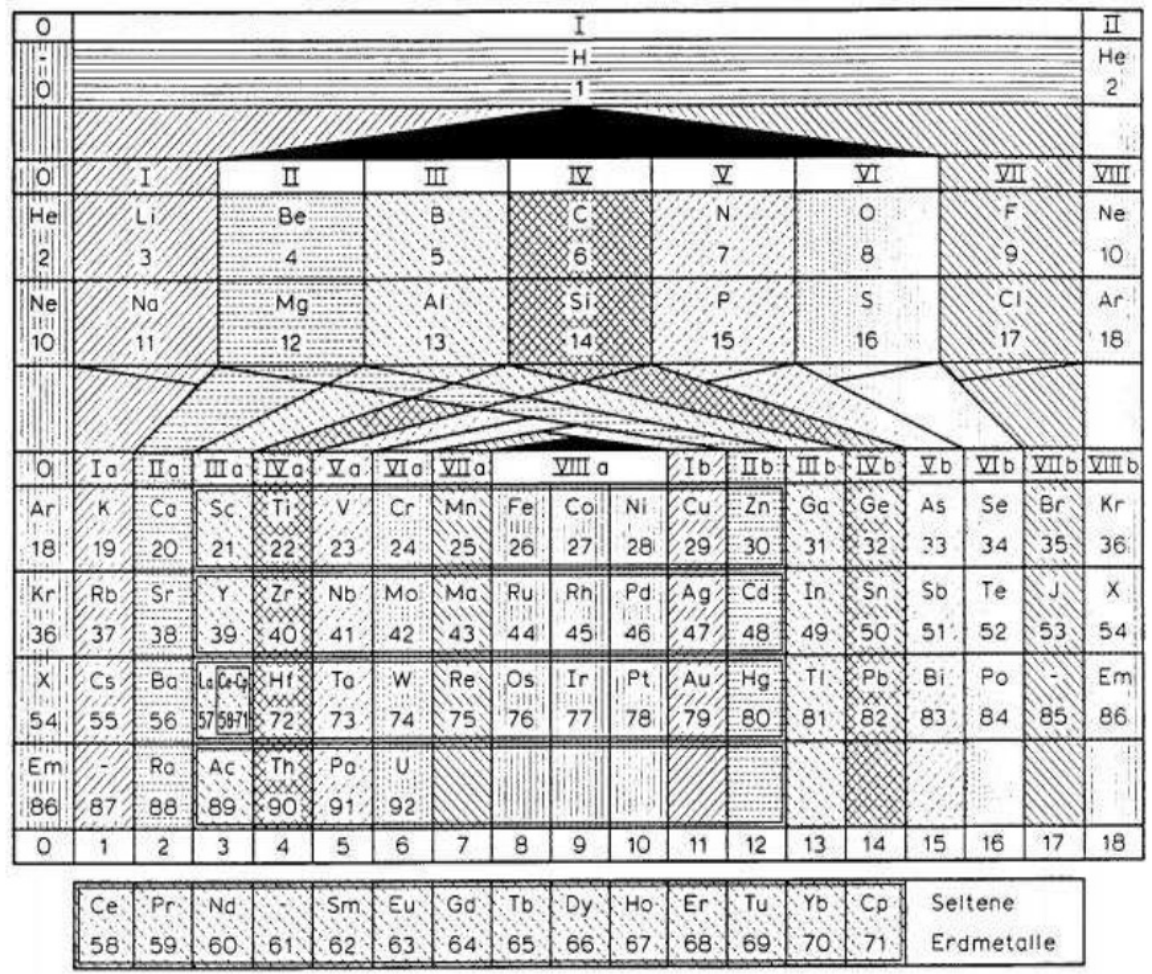

Fonte: Sime, 2000. 
O trabalho recebeu algumas críticas, como é natural na ciência; a que vamos estudar aqui foi arquitetada pela química alemã Ida Noddack (1934). Publicado poucos meses depois do artigo de Fermi, seu artigo é exemplar dos tipos de crítica discernidos por Longino (1990) - inclusive aquela que pode mais claramente revelar os valores metateóricos de uma determinada investigação. Noddack é bastante objetiva nas suas críticas às investigações de Fermi; seu artigo, de três páginas, é assaz didático, como a Conferência Nobel de Curie, e pode ser facilmente lido pelos exotéricos ao círculo de pesquisas em física nuclear e química analítica, inclusive professores de física e química.

Após resumir as metodologias executadas por Fermi para produzir os nêutrons térmicos e para comparar a meia-vida aos elementos vizinhos do urânio, ela afirma, assertivamente: “[e]sse método de prova não é válido [...] não fica claro por que ele não investigou o elemento polônio (84) e por que ele decidiu parar as

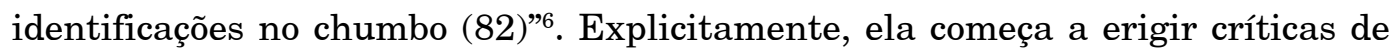
natureza evidencial e conceitual. Faz uma crítica evidencial e, em consequência, aponta lacunas na solidez conceitual, porque nesta citação, ela aponta uma inconsistência nas escolhas metodológicas. Ela continua explicando a razão de achar inconsistente: Fermi investigava uma reação de radioatividade induzida, mas parou suas identificações no limite dos decaimentos radioativos naturais. "Fermi, portanto, deveria ter comparado seu novo radioelemento a todos os elementos conhecidos". Ela continua, com o apoio de conhecimento evidencial, da química analítica: "vários elementos precipitarão com o dióxido de manganês se estiverem presentes como compostos, átomos ou colóides em uma solução de ácido nítrico". Ela afirma que reproduziu o método de precipitação de Fermi e determinou química e espectroscopicamente que o precipitado poderia conter variados elementos, como o tálio e o silício em quantidade total e elementos como o bismuto e o cobalto, em quantidades parciais.

Ainda nesta citação, ela dá início a outra crítica conceitual, mais uma vez consequente de uma crítica evidencial, acerca da coerência da hipótese com teorias já aceitas. Isso porque Fermi não descartou, em sua investigação, a identidade da meia-vida de 13 minutos com o polônio. Mais uma vez, pauta sua crítica evidencial em sólidos conhecimentos evidenciais da química analítica, asseverando ter precipitado o polônio quase completamente com o dióxido de manganês. "Portanto, a prova de que o novo elemento (13 minutos) tem o número atômico 93 não é bem-sucedida 
em nenhum sentido, já que o método para eliminar outras possibilidades não foi levado a cabo".

Suas críticas agora culminam com uma crítica da relevância das evidências para suportar a hipótese, categoria compreendida por Longino (1990) como a mais importante, por sua capacidade de revelar os valores envolvidos na escolha de determinada hipótese.

Pode-se assumir igualmente bem que, quando os nêutrons são usados para produzir desintegrações nucleares, algumas novas reações distintamente novas ocorrem, que não foram observadas previamente com o bombardeamento nuclear com prótons ou partículas alfa. No passado, achava-se que as transmutações dos núcleos só ocorrem com a emissão de elétrons, prótons ou átomos de hélio, de forma que os elementos pesados têm apenas pequenas alterações de massa, produzindo elementos vizinhos. Quando núcleos pesados são bombardeados por nêutrons, é concebível que o núcleo se quebre em vários grandes fragmentos, que seriam, é claro, isótopos de elementos conhecidos, mas que não seriam vizinhos do elemento irradiado.

Em outras palavras, Noddack (1934) aponta que, diante das evidências, uma hipótese totalmente diferente poderia ser igualmente erigida - a de que a irradiação com nêutrons pudesse causar uma quebra dos núcleos em outros, de massa intermediária. Uma análise mais cuidadosa de seu artigo, contudo, pode levar a pensar que, de fato, essa segunda hipótese parece mais suportada pelos conhecimentos canônicos da química analítica, afinal. De todo modo, o que fica claro aqui é a identificação de Noddack da subdeterminação da hipótese de Fermi pelas evidências por ele apresentadas; revela a preferência de Fermi pelo ineditismo da descoberta dos transurânicos e uma subordinação de sua concepção de coerência com os cânones da física, mesmo que suas metodologias demandassem uma associação coerente com os cânones da química analítica.

Para efeitos de completude de argumento, Noddack (1934) ainda enfatiza que, se o urânio tivesse realmente produzido o elemento 93 por decaimento beta, possivelmente este transurânico também produziria o elemento 94, pelo mesmo processo. Quimicamente, seria de relativa simplicidade separá-los, e poderia determinar com certeza a afirmação da produção de transurânicos, em relação aos quais o próprio Fermi se demonstrava cauteloso, mas que tinha despertado grande alvoroço na mídia e na comunidade científica. Ela finaliza suas críticas aos transurânicos, então, com mais uma crítica de natureza evidencial. 


\section{Considerações educacionais}

Neste trabalho, busquei ir além da defesa filosófica de que se fazem juízos de valor na ciência; quis pormenorizar aspectos de duas teses filosóficas que, apesar de nem sempre concordarem entre si, podem se configurar como instrumentos analíticos bastante interessantes para a leitura de certas fontes primárias. No I Encontro sobre História e Filosofia no Ensino de Física do Sul do Brasil, Ricardo Karam defendeu que não há necessidade de se ter medo das fontes primárias no ensino, posição com a qual concordo.

Um dos aspectos que a tradição didática francesa conseguiu revelar foi o de que os conhecimentos científicos sofrem muitas transformações antes de chegar em sala de aula. Quase quatro décadas se passaram desde que Chevallard (1991) ensinou primeiramente a concepção de transposição didática, mas mesmo nos mais novos livros didáticos aprovados pelo Plano Nacional do Livro Didático, e sobretudo nos livros tradicionalmente usados no ensino superior, encontram-se as marcas dos processos descontextualizadores tão bem detalhados pelo didata francês. Não é para menos: nossa concepção de que é preciso ensinar todos os conceitos e fenômenos da física em dois, ou no máximo três anos, demanda que o professor tenha um livro de apoio que dê conta de todo esse conteúdo, com um encadeamento lógico e acumulativo. Mas (e felizmente), não só de livros vive a educação científica; o professor é, ele próprio, uma verdadeira fonte de conhecimento sobre ciência e, mais importante, o agente transformador do seu conhecimento e daquele presente no livro, mediador da aprendizagem do aluno.

Com mais facilidade, vislumbro possibilidades do uso de fontes primárias tipo artigos científicos no ensino superior, apesar de ver potencialidades para algumas Conferências Nobel também para o ensino básico. Para o caso dos dois trabalhos que apresentei aqui, vejo que têm claro espaço até mesmo no ensino básico e, mais ainda, podem demandar um salutar trabalho multidisciplinar entre docentes de física e química. É interessante que o atual documento regulador mínimo dos currículos brasileiros, a BNCC - Base Nacional Comum Curricular (BRASIL, 2018), demanda que o aluno tenha contato com a Física e a Química desde os anos finais do ensino fundamental. No nono ano, aliás, a unidade temática "Matéria e Energia" prevê a exploração dos seguintes objetos de conhecimento: aspectos quantitativos das transformações químicas, estrutura da matéria, radiações e 
suas aplicações na saúde. Ora, um belo espaço para fazer as discussões sugeridas aqui neste trabalho.

As Ciências da Natureza para a etapa do ensino médio preconizam que

A contextualização social, histórica e cultural da ciência e da tecnologia é fundamental para que elas sejam compreendidas como empreendimentos humanos e sociais [...] a contextualização histórica não se ocupa apenas da menção a nomes de cientistas e a datas da história da Ciência, mas de apresentar os conhecimentos científicos como construções socialmente produzidas, com seus impasses e contradições, influenciando e sendo influenciadas por condições políticas, econômicas, tecnológicas, ambientais e sociais de cada local, época e cultura [...] propõe-se, por exemplo, a comparação de distintas explicações científicas propostas em diferentes épocas e culturas e o reconhecimento dos limites explicativos das ciências, criando oportunidades para que os estudantes compreendam a dinâmica da construção do conhecimento científico [...] Os processos e práticas de investigação merecem também destaque especial nessa área. Portanto, a dimensão investigativa das Ciências da Natureza deve ser enfatizada no Ensino Médio, aproximando os estudantes dos procedimentos e instrumentos de investigação (BRASIL, 2018, p. 549, 550).

Apesar das discordâncias acerca do documento e seu papel político na educação básica brasileira (SELLES, 2018; MARTINS, 2018), ele é inescapável. Por ora, um novo paradigma educacional brasileiro se iniciou, em que impera uma visão multidisciplinar do ensino de ciências, inclusive com a produção corrente de livros didáticos. É necessário fazer o melhor que podemos diante das condições colocadas e, dentro das proposições da BNCC, compreendo que há espaço para a criatividade docente e, inclusive, para as discussões que aqui propus, justamente pelo caráter interdisciplinar entre química, física, história e filosofia da ciência que as fontes primárias analisadas desta feita podem proporcionar.

É preciso reiterar que busquei apresentar as duas filosofias da ciência como instrumento heurístico, especialmente profícuas para a análise de alguns documentos científicos com potencialidades didáticas. É certo, porém, que a perspectiva de Laudan (1984) pode ser ampliada para agregar mais condições sociais, que mostrem melhor as entradas e saídas de demandas externas à ciência na produção do conhecimento científico. Há documentos científicos com potencial didático que, seguramente, demandariam uma visão mais sociológica, sobretudo se o objetivo do educador for o de aprofundar uma contextualização mais cultural de certos episódios científicos. Porém, a capacidade analítica da tese de Laudan (1984), por mais internalista e rígida que pareça, é capaz de guiar a leitura de variadas Conferências Nobel, especificamente por seu caráter justificativo. 
Outro ponto que não quero deixar escapar é de que entendo que nem todos os documentos primários são didatizáveis, mas há muitos que são. $\mathrm{O}$ primeiro artigo de Marie Curie (1898) é ótimo exemplo, assim como os de Geiger e Marsden (1909) sobre o espalhamento de partículas alfa, ou o de Meitner e Frisch (1939) com a explicação física da fissão nuclear. Não são autoevidentes, claro, e por isso demandam planejamento e estudo por parte do educador, o processo descrito por Chevallard (1991) como transposição didática interna. Ainda assim, são fontes de inestimáveis aspectos metodológicos da ciência, que ajudam a perfeiçoar a necessária, mas superficial defesa de que a ciência é conhecimento estruturado e social. Neste sentido, são salutares ações como a da Revista da Sociedade Brasileira de História da Ciência em apresentar traduções de fontes primárias.

Como já defendi, as Conferências Nobel são, por natureza, documentos científicos que passaram, de certa forma, por uma didatização, porque são endereçadas a leigos. Vale ressaltar, contudo, que elas não devem ser tomadas como verdade histórica. Como bem afirmou Whitaker (1979), esses documentos podem envolver uma narrativa heroica ou de até de razoável deferência a outros trabalhos, já que são a história contada por um cientista em particular. Para além disso, cabe pensar nos valores envolvidos na própria escolha do nobelista, que também são impregnadas dos valores do Comitê Nobel e dos eminentes cientistas que indicam potenciais laureados para um dado ano. Essas escolhas, aliás, passam por frequentes controvérsias, como bem explora Feldman (2000). Nada disso é perfeitamente objetivo; aliás, se não se pode garantir uma objetividade tradicional e ontológica aos conhecimentos erigidos pela ciência dura, Kragh (2001) aponta que essa é, também, uma tarefa elusiva para a história da ciência.

Nesse sentido, penso ser francamente interessante a tese de Longino (1990) da ciência como conhecimento social. Para além da heurística da crítica, ela mostra como detectar os valores contextuais que atuam de forma constitutiva ou não na ciência. Serve para entender a influência da cultura, a dinâmica intersubjetiva, os panos de fundo metacientíficos e, inclusive, os valores mediadores da escolha de um nobelista. As Ciências da Natureza devem ser "compreendidas como empreendimentos humanos e sociais" (BRASIL, 2018, p. 549). Essa é uma máxima aventada pelas pesquisas em educação científica há algumas décadas. Mas como fazer isso? Vejo grandes potenciais nas ideias de Longino (1990) que, por um 
lado, não busca fugir do argumento da subdeterminação mas, por outro, mostra que é justamente nas negociações que se constroem as fundamentações lógicas da ciência. Em tempos de negacionismo, muitas vezes baseados em ideias acerca da irracionalidade da ciência, é alentador conhecer e conseguir operacionalizar uma tese filosófica que indique a dimensão lógica da ciência justamente em seu caráter social e subdeterminado.

Por fim, ressalto que escolhi aqui os trabalhos de duas mulheres e essa escolha não foi sem razão. Vemos um crescimento nos movimentos feministas no século 21, com a consequente preocupação sobre o tema na educação científica. Pesquisas têm demonstrado que exemplos de mulheres cientistas na educação podem ajudar a manter as meninas interessadas pela ciência. É essencial enfatizar que as mulheres ainda são objetos de investigações científicas, muitas vezes impregnadas de valores androcêntricos. A tese de Longino (1990) tem também o poder de esclarecer esses meandros. Para um educador interessado em agregar às discussões bastante internalistas que fiz aqui, vale frisar ainda dois pontos: apenas por uma manobra burocrática, Marie Curie foi laureada em 1903 com o Prêmio Nobel da física, quando um grupo de eminentes físicos franceses bastante familiarizados com suas pesquisas indicaram apenas Henri Becquerel e Pierre Curie, com uma narrativa fantasiosa de pesquisas entre os dois (QUINN, 2011; CORDEIRO, 2013). Ainda, o artigo de Noddack, embora conhecido por todos os grupos de pesquisa em física nuclear da década de 1930, foi sumariamente ignorado. Hook (2007) defende que a prematuridade da descoberta da fissão nuclear foi um caso de "dissonância interdisciplinar" e desconsidera, também sumariamente, que o fato de que ela era mulher possa ter tido alguma influência entre os outros pesquisadores. Associando a história do patriarcado à visão de Helen Longino (CORDEIRO, 2020), temos as ferramentas para sermos céticos em relação a neutralidade de gênero em ambos os casos. 


\section{Science and Values: an epistemologically guided analysis of primary historical sources}

\section{Abstract}

In this paper, the dynamic between science and values is introduced from its origins, in the logical question of underdetermination. Its general aim is to present two philosophical theses which show special heuristic abilities for the analysis of primary historical sources: Longino's science as social knowledge and Laudan's reticulated model of justification. Laudan's model is used to analyse Marie Curie's 1911 Nobel Lecture, showing the articulations between evidence, methodology and values to justificate radium as a well defined element and, ultimately, a shift on Chemistry itself. Longino's science as social knowledge, especially the categories of intersubjective criticism she devises, supplies Ida Noddack's paper "On element 93" with the comprehension of how evidential and conceptual criticisms can unfold the values that mediated Fermi's hypotheses of the production of transuranium elements, as well as her premature suggestion of the nuclear fission.

Keywords: Underdetermination. Justification. Radioactivity. Intersubjective Criticism. Nuclear Fission.

\section{Notas}

1 <https://www.nobelprize.org/> . Acesso em 1 de agosto de 2021.

2 Marie Curie quase não foi nomeada, devido a não ter sido indicada no ano de 1903, em um episódio de claro desdém por seu trabalho, protagonizado por eminentes físicos franceses que a conheciam e que não a nomearam ao Comitê, recorrendo a uma narrativa fantasiosa. A situação foi revertida por certas manobras burocráticas. Para mais detalhes, ver Cordeiro (2013) e Quinn (2011).

3 Usarei o termo 'radiocientistas' para designar todos aqueles que trabalham em radioatividade, sejam químicos, físicos ou outros.

4 Hoje, entende-se a partícula alfa como o núcleo de hélio; na época, contudo, o modelo atômico nuclear de Bohr-Rutherford ainda não fora construído.

5 A Conferência Nobel de Marie Curie (1911, 1966) foi traduzida por mim, em artigo intitulado "As Conferências Nobel de Marie e Pierre Curie: a gênese da radioatividade no ensino" (CORDEIRO; PEDUZZI, 2010). Neste trabalho, a paginação refere-se às páginas da referida tradução. A versão original pode ser vista no site do Prêmio Nobel, em <https://www.nobelprize.org/prizes/chemistry/1911/marie-curie/lecture/>. Acesso em 27 de julho de 2021.

6 As citações aqui apresentadas são traduções da tradução para o inglês do artigo de Noddack, feita por H. G. Graetzer e disponível em <https://www.chemteam.info/Chem-History/Noddack-1934.html>. Acesso em 31 de julho de 2021. Por isso, a paginação de todas as citações diretas não consta no corpo deste artigo. 


\section{Referências}

BRASIL. Ministério da Educação. Base Nacional Comum Curricular ( $3^{a}$ edição revisada). Brasília, 2018.

CHEVALLARD, Y. La transposition didactique (Du savoir savant au savoir enseigné). Grénoble: Edition la Pensée Sauvage, 1991.

CORDEIRO, M. D. Questões de gênero na ciência e na educação científica: uma discussão centrada no Prêmio Nobel de Física de 1903. In: Atas do IX Encontro Nacional de Pesquisa em Educação em Ciências. Águas de Lindoia, 2013.

CORDEIRO, M. D. Reflexões da história do patriarcado para esses tempos de pós-verdade. Caderno Brasileiro de Ensino de Física, v. 37, n. 3, 2020.

CORDEIRO, M. D., PEDUZZI, L. O. Q. As Conferências Nobel de Marie e Pierre Curie: a gênese da radioatividade no ensino. Caderno Brasileiro de Ensino de Física, v. 27, n. 3, dez. 2010.

CURIE, M. Rayons émis par les composés de $1 \square$ uranium et du thorium. Comptes Rendus Hebdomadaires de l'Académie des Sciences de Paris. Paris, v. 126, t. 2, p. 1101 -1103, 1898.

CURIE, M. Radium and the new concepts in chemistry (1911). In: Nobel Lectures, Chemistry 1901-1921. Amsterdam: Elsevier, 1966.

FELDMAN, B. The Nobel Prize. 1. ed. Nova York: Arcade Publishing, 2000.

FERMI, E. Possible production of elements of atomic number higher than 92. Nature, v. 133, p. 898, 1934.

GEIGER, H., MARSDEN, E. On a diffuse reflection of the alpha particles. Proceedings of the Royal Society. Londres, v. 82, p. 495 - 500, 1909.

HAHN, O.; STRASSMANN, F. Über den Nachweis und das Verhalten der bei der Bestrahlung des Urans mittels Neutronen entstehenden Erdalkalimetalle. Die Naturwissenschaften, v. 27, p. 11, jan. 1939a.

HOOK, E. B. Dissonância interdisciplinar e prematuridade: a sugestão de Ida Noddack de fissão nuclear. In: HOOK, E. B. (org,). Prematuridade na descoberta científica: sobre resistência e negligência. São Paulo: Perspectiva, 2007.

KRAGH, H. Introdução à Historiografia da Ciência. Porto: Porto Editora, 2001.

KUHN, T. S. A estrutura das revoluções científicas. São Paulo: Perspectiva, 9ª ed., 2006.

KUHN, T. S. (1973) Objetictividade, juízo de valor e escolha teórica. In: A Tensão Essencial. Lisboa: Edições 70, p. 363, 2009.

LAUDAN, L. Science and values: the aims of science and their role in scientific debate. Berkeley, Los Angeles: University of California Press, 1984.

LONGINO, H. Science as a social knowledge: values and objectivity in scientific inquiry. Princeton: Princeton University Press, 1990.

MARTINS, A. F. P. Editorial: Sem carroça e sem bois: breves reflexões sobre o processo de elaboração de "uma" BNCC. Caderno Brasileiro de Ensino de Física, v. 35, n. 3, 2018. 
MCGRAYNE, S. B. Mulheres que ganharam o Prêmio Nobel em Ciências: suas vidas, lutas e notáveis descobertas. Tradução: Maiza F. Rocha e Renata Brant de Carvalho. São Paulo: Marco Zero, 1995.

MEITNER, L.; FRISCH, O. R. Desintegration of uranium by neutrons: a new type of nuclear reaction. Nature, v. 143, p. 239-240, fev. 1939.

NODDACK, I. Über das Element 93. Zeitschrift fur Angewandte Chemie, v. 47, p. 653, set. 1934.

QUINN, S. Marie Curie: a life (kindle e-book). Plunkett Lake Press, 2011.

SELLES, S. E. Editorial: A BNCC e a Resolução CNE/CP no 2/2015 para a formação docente: a “carroça na frente dos bois". Caderno Brasileiro de Ensino de Física, v. 35, n. 2, 2018.

SIME, R. L. The search for transuranium elements and the discovery of nuclear fission. Physics in Perspective, v. 2, p. 48, 2000.

WHITAKER, M. A. B. History and quasi-history in physics education - part 2. Physics Education, v. 14, n. 4, p. 239-242, mai. 1979. 